throughout the follow-up period the child has demonstrated evidence of ongoing neurologic improvement.

This represents the youngest reported patient to be supported successfully to transplant with the PediMag pump. In addition, the PediMag was later used as posttransplant ECMO support in combination with the QUADROX-iD oxygenator. When using $1 / 4-$ inch tubing connections with minimal length, the priming volume of the ECMO circuit is less than $160 \mathrm{~mL}$, and the cannulas are readily available and easy to implant. Thrombotic complications continue to plague mechanical assistance in this age group, highlighting the importance of ongoing vigilance for areas of turbulence or stasis while the patient is receiving device support. In light of this, we endorse the use of coated tubing, connectors, and cannulas, and we prefer to limit the complexity of the circuit where possible. Relative to our previous mechanical circulatory assist experience in children ${ }^{3}$ with the CentriMag (Thoratec Corporation, Pleasanton, Calif) at low flow, we have found the PediMag to be less prone to thrombus while being comparably easy to implant and use postoperatively.

\section{References}

1. Stiller B, Benk C, Schlensak C. Mechanical cardiovascular support in infants and children. Heart. 2011;97:596-602.

2. Brancaccio G, Amodeo A, Ricci Z, Morelli S, Gagliardi MG, Iacobelli R, et al Mechanical assist device as a bridge to heart transplantation in children less than 10 kilograms. Ann Thorac Surg. 2010;90:58-62.

3. Hirata Y, Charette K, Mosca RS, Quaegebeur JM, Chen JM. Pediatric application of the Thoratec CentriMag BiVAD as a bridge to heart transplantation. J Thorac Cardiovasc Surg. 2008;136:1386-7.

\title{
Robotic transthoracic esophagectomy in the prone position: Experience with 32 patients with esophageal cancer
}

\author{
Shailesh Padmakar Puntambekar, MS, Neeraj Rayate, MS, DNB, Sourabh Joshi, MS, and \\ Geetanjali Agarwal, MS, Pune, India
}

The first case description of thoracoscopic esophagectomy aided by the da Vinci robotic system (Intuitive Surgical, Inc, Sunnyvale, Calif) was published in 2004 by Kernstine and colleagues. ${ }^{1}$ We report here our singleinstitution experience of 32 robot-assisted esophagectomies with the da Vinci robot in which mobilization of the esophagus was done with the patient in the prone position.

\section{OPERATIVE TECHNIQUE}

The patient was placed in the prone position on an operative sandbag. The robotic cart was situated to the left side of the patient. The operative trocars for the robot (one 12$\mathrm{mm}$ port for the camera and two 8-mm ports for the arms) were placed (Figure 1). The first port was inserted 1 finger-breadth below and posterior to inferior angle of scapula in the 5th or 6th intercostal space. Two 8-mm trocars were positioned under direct thoracoscopic vision in a vertical line at a distance of $5 \mathrm{~cm}$ and in triangulation with the camera port in the third and eighth intercostal spaces, respectively. One $10-\mathrm{mm}$ port for the assistant was placed

From the Galaxy Care Laparoscopy Institute, Pune, Maharashtra, India.

Disclosures: Authors have nothing to disclose with regard to commercial support.

Received for publication Aug 26, 2010; revisions received March 18, 2011; accepted

for publication March 28, 2011; available ahead of print May 2, 2011.

Address for reprints: Shailesh Padmakar Puntambekar, MS, Galaxy Care Laparos-

copy Institute, Pune, Maharashtra 411004, India (E-mail: shase63@gmail.com).

J Thorac Cardiovasc Surg 2011;142:1283-4

0022-5223/\$36.00

Copyright (c) 2011 by The American Association for Thoracic Surgery

doi:10.1016/j.jtcvs.2011.03.028 between the left working port and the camera port. This was used for suction and clip application. Pneumoinsufflation was created at a pressure of $7 \mathrm{~mm} \mathrm{Hg}$.

With the patient in a prone position, the esophagus falls anteriorly out of its normal position, which creates natural tension and simplifies dissection. We used Maryland bipolar forceps in left arm and hot shears (scissors with monopolar current) in right arm of the robot. The procedure began with the incision of the visceral pleura between the esophagus

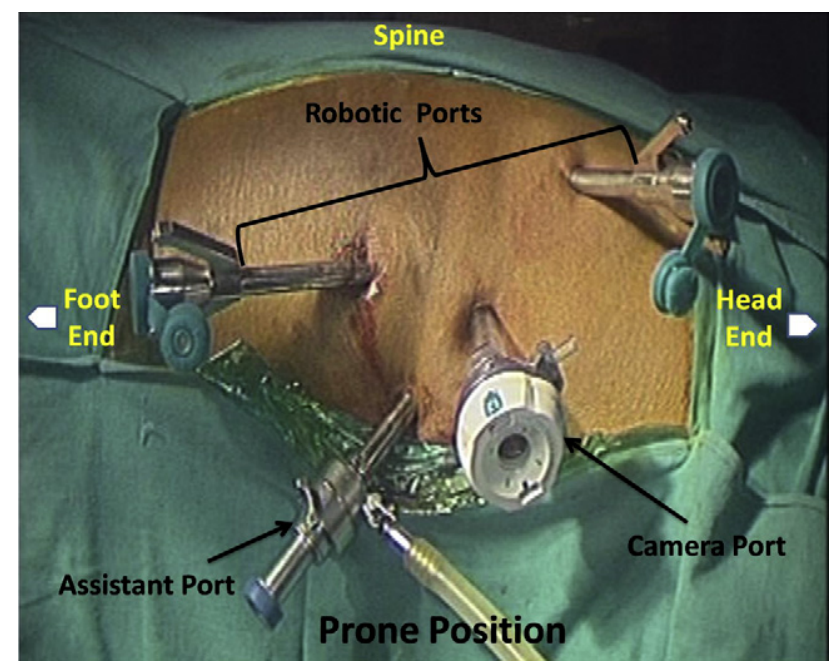

FIGURE 1. Instrumentation for transthoracic esophagectomy with the da Vinci robotic system (Intuitive Surgical, Inc, Sunnyvale, Calif). 
TABLE 1. Comparison with other series

\begin{tabular}{|c|c|c|c|}
\hline & 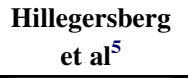 & $\begin{array}{l}\text { Bodner } \\
\text { et } \mathbf{a l}^{4}\end{array}$ & $\begin{array}{c}\text { Our } \\
\text { series }\end{array}$ \\
\hline No. of patients & 47 & 6 & 32 \\
\hline Conversion (no.) & $7(15 \%)$ & 0 & 0 \\
\hline Recurrent palsy (no.) & $9(19 \%)$ & - & $2(6.2 \%)$ \\
\hline $\begin{array}{l}\text { Respiratory } \\
\text { complications (no.) }\end{array}$ & $21(45 \%)$ & - & $2(6.2 \%)$ \\
\hline $\begin{array}{l}\text { Anastomotic leak } \\
\text { (no.) }\end{array}$ & $10(21 \%)$ & - & $3(9.3 \%)$ \\
\hline Chyle leak (no.) & $6(13 \%)$ & 1 & $3(9.3 \%)$ \\
\hline $\begin{array}{l}\text { Mediastinal lymph } \\
\text { nodes (median and } \\
\text { range) }\end{array}$ & $29(8-68)$ & $12(8-19)$ & $20(9-28)$ \\
\hline $\begin{array}{l}\text { Robot assisted thoracic } \\
\text { procedure blood loss } \\
\text { (mL, median and } \\
\text { range) }\end{array}$ & $250(0-800)$ & 一 & $80(40-200)$ \\
\hline $\begin{array}{l}\text { Thoracoscopic time } \\
\text { (min, median and } \\
\text { range) }\end{array}$ & $180(120-240)$ & $173(160-190)$ & $100(80-160)$ \\
\hline $\begin{array}{l}\text { Total operative time } \\
\text { (min, median and } \\
\text { range) }\end{array}$ & $450(360-550)$ & - & $210(180-300)$ \\
\hline
\end{tabular}

and the lung just inferior to the azygos vein. This helped in keeping the esophagus attached to the pleura on the aortic side. More than 3 fourths of the circumference of the esophagus was mobilized in this way from the cranial to the caudal direction. The plane of dissection was outside the vagus. The posterior large direct aortic branches were then clipped, and the small branches were cauterized with bipolar forceps. This completed the mobilization of the esophagus all around. The caudal limit of the dissection was the hiatus. The same dissection was continued in the supra-azygos region. The vagal fibers going to the bronchus were preserved. The azygos vein was preserved. Complete mobilization of the esophagus was achieved. The specimen also included the lower and middle mediastinal, subcarinal, and right paratracheal nodes. The thoracic duct was identified and clipped in all cases. Laparoscopic gastric mobilization of stomach with lymphadenectomy, gastric conduit and anastomosis in the neck were same as described in our previous publication. ${ }^{2}$

\section{RESULTS}

This series demonstrates the technical feasibility, safety, and reproducibility of performing the procedure with the patient in the prone position with all the other advantages of robotic and minimally invasive surgery. The port position and the patient position were different from those in the other 3 series of robotic esophagectomy published to date (Table 1). ${ }^{1,3-5}$ No patient required conversion either to thoracoscopy or to thoracotomy. The mean total operative time was 210 minutes (range, 180-300 minutes), and the mean thoracoscopic time was 100 minutes (range, 80-160 minutes). The average blood loss in our series was $80 \mathrm{~mL}$ (range, 40-200 mL). The reduced blood loss may have been related to the 3-dimensional view and magnification of the robot. The mean mediastinal lymph node yields in our series were 20 mediastinal nodes (range, 9-28 nodes) and 16 abdominal nodes (range, 11-26 nodes), which were the almost same as our yields with thoracoscopic surgery. ${ }^{2}$ Two of our patients had pulmonary complications. Our series had 1 postoperative chyle leak. The incidence of anastomotic leakage in our series was 9.3\% (3/32). All of these complications were managed conservatively. The median hospital stay was 9 days (range, 5-20 days).

\section{DISCUSSION}

Robotic esophagectomy seems a better alternative than thoracoscopic esophagectomy. Having performed both, we consider that the operative stress to surgeon is much less with the robotic procedure. In our experience, the magnification, the 3-dimensional view, and the 7 degrees of freedom led to decreased blood loss and better dissection. Randomized controlled trials are needed to compare open surgery, thoracoscopic surgery, and robotic surgery to determine at last the right approach for esophagectomy.

\section{References}

1. Kernstine KH, DeArmond DT, Karimi M, Van Natta TL, Campos JH, Yoder MR, et al. The robotic, 2-stage, 3-field esophagolymphadenectomy. J Thorac Cardiovasc Surg. 2004;127:1847-9. Erratum in: J Thorac Cardiovasc Surg. 2007;134: 959.

2. Puntambekar SP, Agarwal GA, Joshi SN, Rayate NV, Sathe RM, Patil AM. Thoracolaparoscopy in the lateral position for esophageal cancer: the experience of a single institution with 112 consecutive patients. Surg Endosc. 2010;24: 2407-14.

3. van Hillegersberg R, Boone J, Draaisma WA, Broeders IA, Giezeman MJ, Borel Rinkes IH. First experience with robot-assisted thoracoscopic esophagolymphadenectomy for esophageal cancer. Surg Endosc. 2006;20:1435-9.

4. Bodner JC, Zitt M, Ott H, Wetscher GJ, Wykypiel H, Lucciarini P, et al. Roboticassisted thoracoscopic surgery (RATS) for benign and malignant esophageal tumors. Ann Thorac Surg. 2005;80:1202-6.

5. Boone J, Schipper ME, Moojen WA, Borel Rinkes IH, Cromheecke GJ, van Hillegersberg R. Robot-assisted thoracoscopic oesophagectomy for cancer. $\mathrm{Br} \mathrm{J}$ Surg. 2009;96:878-86. 